\title{
EL REGIMEN DE LA ENCOMIENDA EN UNA ZONA MINERA DE LA NUEVA GRANADA. LOS INDIOS DE LA PROVINCIA DE PAMPLONA A FINALES DEL SIGLO XVI (1549-1623) ${ }^{1}$
}

\author{
Jorge Augusto Gamboa Mendoza \\ Universidad Pedagógica Nacional, Bogotá
}

\section{INTRODUCCION}

El establecimiento del sistema de la encomienda implicó profundos cambios para las poblaciones nativas de la América española. Los sistemas tradicionales de organización social y de producción se vieron afectados en la medida en que las nuevas autoridades reemplazaron a las tradicionales y comenzaron a exigir una serie de bienes y servicios, como parte de las prerrogativas otorgadas por la Corona a los conquistadores. Sin embargo, el tributo no era un elemento desconocido para estas comunidades, ya que en muchos casos se practicaba como parte del reconocimiento

1 El autor agracede a la doctora Pilar Martínez de Brahim, Gerente del Fondo Mixto para la Promoción de la Cultura y las Artes del Norte de Santander por la colaboración brindada para la elaboración de este trabajo. 
hacia sus propias autoridades. Con bastante frecuencia los encomenderos tuvieron que adaptar este mecanismo a sus propios intereses, situándose como un poder nuevo, por encima del Cacique. Pero en aquellas comunidades que no tenían caciques o jefes estables, como las bandas de cazadores-recolectores o las sociedades tribales con "gobierno mínimo", ${ }^{2}$ los españoles se vieron en la necesidad de imponer Caciques y enseñar a los indios a obedecerlos. Esto con el fin de que sirvieran de mediadores entre ellos y la comunidad, facilitando de esta manera su gobierno y la obtención de tributos. ${ }^{3}$

Pero exceptuando estos casos en los cuales se modificó radicalmente la organización política de las comunidades, la introducción del sistema de encomiendas no significó una ruptura total con el pasado. En la costumbre del tributo se mezclaron elementos tradicionales de los indígenas con elementos nuevos que introdujeron los encomenderos, tal como ha sido señalado por autores como Charles Gibson. ${ }^{4}$

En las páginas siguientes se hará un análisis del sistema de encomiendas que se impuso en la Provincia de Pamplona del Nuevo Reino de Granada a mediados del siglo XVI. El análisis va orientado a demostrar que en esta región no se estableció una sola forma de encomiendas, sino que las características de éstas variaron de acuerdo a una serie de factores, como la organización política de la sociedad indígena sometida o las riquezas naturales disponibles. Cuando estos factores variaban, la naturaleza de la relación entre los encomenderos y los indios, expresada a través del tributo y los servicios personales, también cambiaba. Las comunidades tenían cierto margen de negociación. No todo era violencia y malos tratos, ya que los encomenderos corrían el riesgo de perder a sus indios cuando la explotación se hacía intolerable para estos, lo que sucedía sobre todo en las co-

2 El término "gobierno mínimo" ha sido acuñado por Lucy Mair en su obra Gobierno Primitivo, Buenos Aires, Amorrortu Editores, 1970, p. 62. Se trata de organizaciones políticas como las observadas entre los Nuer, los Hazda o los Anuak del África Oriental, los cuales están divididos en aldeas o grupos independien tes políticamente, donde existen líderes respetados por la comunidad debido a sus cualidades para la caza, a su sabiduría, sus poderes rituales, etc. Estos líderes suelen guiar a sus gentes y sus opiniones son altamente tenidas en cuenta, pero no tienen derecho a dar órdenes ni pueden exigir una obediencia absoluta.

3 Esto sucedió por ejemplo con los indios de la región de Muzo, que eran gobernados por los ancianos de cada grupo y sólo nombraban jefes en caso de guerra. Luis Enrique Rodríguez, Encomienda y vida diaria entre los indios de Muzo (;550-1620), Bogotá, Instituto Colombiano de Cultura Hispánica, 1995.

4 Charles Gibson, "Las Sociedades Indias bajo el dominio español". Historia de América Latina, Barcelona, Editorial Crítica, t. 4, pp. 157-188. 
munidades donde no había caciques ni organizaciones políticas fuertes, hacia la frontera norte de la provincia. Allí era muy fácil escapar al control de los españoles y, por lo tanto, muy difícil obligarlos a obedecer. Por eso los conquistadores tuvieron que atraer a estos grupos con regalos y otros métodos pacíficos, para acostumbrarlos gradualmente a trabajar para ellos y a pagar tributos.

La investigación está basada en las Visitas practicadas en 1559 y 1560 por el escribano Cristóbal Bueno y el Oidor Tomás López, respectivamente. Su interés radica en que son documentos bastante tempranos, producidos cuando aún no habían pasado más de 10 años de la llegada de los españoles y las comunidades aún no habían perdido la mayoría de sus rasgos culturales como la lengua, la religión y su organización política y económica. La Visita de Cristóbal Bueno es la más completa de las dos y nos presenta una visión global de la Provincia, con cerca de 120 encomiendas inspeccionadas. ${ }^{5}$ Por el contrario, la Visita de Tomás López se ha conservado de manera muy fragmentaria y solamente ha sobrevivido la información correspondiente a unas 20 encomiendas, cuyos expedientes se encuentran dispersos en varios fondos del Archivo General de la Nación en Santafé de Bogotá. ${ }^{6}$ Sin embargo, su importancia radica en que durante el año que transcurrió entre la primera visita y la segunda, una epidemia de viruelas asoló la región, lo cual trajo una serie de consecuencias que se verán más adelante.

\section{Los sistemas políticos prehispánicos}

Al llegar a la Provincia de Pamplona en 1549, los españoles encontraron una serie de comunidades políticamente independientes, con una organización económica y política heterogénea, aunque parecían tener cierta relación a nivel cultural y lingüístico. Sus costumbres eran similares a las de los Muiscas, habitantes del altiplano Cundiboyacense, según cuenta el cronista Pedro de Aguado, aunque desgraciadamente no brinda mayores detalles. Dentro de las pocas observaciones que hace sobre estos grupos señala,

5 "Visita del escribano Cristóbal Bueno (1559)". Archivo General de la Nación de Santafé de Bogotá (A.G.N.), Visitas de Santander, t. 3. ff. 709r-881v. Citada en adelante como "Visita de Cristóbal Bueno (1559)".

6 Cada vez que se haga referencia a esta Visita se citará como "Visita de Tomás López (1560)" y el fondo del Archivo General de la Nación (Santafé de Bogotá), donde se encuentran los expedientes correspondientes a la encomienda de la cual se esté hablando. 
tiempos de sequías o de hambrunas. En estas comunidades existía la costumbre de reunirse periódicamente para realizar trabajos de interés comunitario o para hacer las labranzas del "curaca". Los Incas, al establecer su dominio aprovecharon esta tradición e implantaron la obligación de trabajar periódicamente para el Estado, creando el sistema de la "mit'a", que a su vez fue tomado y adaptado por los españoles para su propio beneficio. ${ }^{10} \mathrm{Se}$ sabe que los Muiscas también acostumbraban a trabajar en algunas labranzas para sus caciques, a los cuales además entregaban productos como mantas, sal y venados. ${ }^{11}$

No es de extrañar, entonces, que los indios Chitareros, habitantes de la Provincia de Pamplona, tuvieran costumbres similares. Esto se aprecia en los documentos consultados, ya que la estructura política basada en caciques y capitanes estaba aún en pleno funcionamiento hacia 1559. En algunos casos, como en la encomienda de Silos o la de Tangacha, las autoridades tradicionales estaban compuestas por dos niveles de jerarquía, denominados Caciques y Principales. ${ }^{12}$ Sin embargo, lo más frecuente era una organización más simple, con grupos de unas 50 a 100 personas, gobernados por Principales o Capitanes independientes, como en los casos de las encomiendas de Tane y Sentimali. ${ }^{13}$

La autoridad de estos capitanes parece ser menos fuerte que la de los caciques, ya que en algunos casos ellos mismos manifestaron al Visitador que no habían podido obligar a sus sujetos a acudir ante el funcionario de la Corona para realizar el conteo de las personas, porque no le hacían caso. Por ejemplo en algunos pueblos situados en las tierras bajas de la región del río Táchíra, hacia el nororiente de la provincia, donde aún no se había establecido un dominio firme por parte de los españoles en 1559, los capitanes acudieron ante el Visitador pero manifestaron que no habían podido traer a su gente y que tampoco pagaban tributo por haber "dado la paz" muy re-

\footnotetext{
${ }^{10}$ Steve Stern, Los pueblos indígenas del Perú y el desafío de la conquista española, Madrid, Alianza Editorial, 1990 y también Peter Backewell, Mineros de la Montaña Roja, Madrid, Alianza Editorial, 1989.

${ }^{11}$ Carl Langebaek, Mercados, poblamiento e integración étnica entre los Muiscas, Siglo XVI, Bogotá, Banco de la República, 1987.

12 Visita de Cristóbal Bueno (1559), ff. 737r y 823v.

B Ibid. ff, 755r y 823r.
} 
cientemente y por estar el resto de la zona aún sin someter. Así sucedió con encomiendas como la de Cucaraquesa de Juan de Torres, compuesta por tres grupos con su respectivo capitán, o la de Táchira de Nicolás Nieto. ${ }^{14} \mathrm{Al}$ parecer este Valle, junto con el Valle de las Arboledas, situados ambos en las tierras bajas del norte de la provincia, estaban habitados por tribus ${ }^{13}$ independientes gobernadas por capitanes elegidos por su prestigio o sus capacidades para la guerra y no se habían desarrollado estructuras de cacicazgos complejos y hereditarios. Por esta razón y por las dificultades del clima y del terreno, los españoles tuvieron bastantes problemas para someterlos.

Estas estructuras políticas continuaron operando durante mucho tiempo, por lo menos hasta los primeros años del siglo XVII, ya que en Visitas realizadas más de 50 años después, algunas comunidades indígenas aún seguían haciendo las labranzas de sus caciques y dándole algunas mantas y otros productos como una forma de reconocer su autoridad. En el pueblo de Ulaga, por ejemplo, los indios declararon en 1602 que aún conservaban la costumbre de hacer algunas labranzas para el Cacique en reconocimiento de su autoridad. También se conservaba la sucesión matrilineal, y el poder era heredado por el hijo mayor de la hermana. ${ }^{16}$

Dadas estas características de la organización política de los Chitareros, los encomenderos probablemente tuvieron que adaptar el sistema a sus propios intereses, entrando de algún modo a reemplazar a la figura del cacique. De esta forma, las comunidades tributaban ahora doblemente: al encomendero y al cacique, quien siguió conservando algunas prerrogativas, dada su condición de intermediario entre los españoles y la comunidad.

\section{El establecimiento del régimen de la encomienda}

Después de culminada la conquista de la Provincia de Pamplona en los meses finales del año de 1549, los jefes de la expedición procedieron a

14 Ibid. ff, 753v y 761v.

15 El término "tribu" se refiere a un tipo de organización política y social, que se encuentra en un nivel interme dio entre las "bandas" de cazadores-recolectores y los "cacicazgos". Marshall Sahlins, Las sociedades tribales, Barcelona, Editorial Labor, 1984.

16 Visita del Corregidor Antonio Beltrán de Guevara a la Provincia de Pamplona en 1602. En adelante citada como "Visita de Beltrán de Guevara (1602)". A.G.N. (Santafé de Bogotá). Visitas de Santander, t. 3, ff. 559689. 
repartir los indios que habían sometido, para que los miembros de la hueste pudieran establecerse en la ciudad recién fundada y tuvieran medios para desarrollar empresas agrícolas y mineras. En cada comunidad sometida, el cacique y las autoridades tradicionales tuvieron que realizar largas negociaciones con los encomenderos para establecer el tributo que de ahora en adelante le pagarían. Aunque las Nuevas Leyes, que señalaban la forma de tasar los tributos por parte de las autoridades coloniales ya estaban vigentes por aquel entonces, su aplicación en las tierras recién conquistadas era nula debido a la ausencia casi total de los representantes oficiales de la Corona. Como la tasación debía esperar a que una autoridad colonial de alto rango como un Gobernador o un Visitador la estableciera oficialmente, podían pasar décadas sin que esta diligencia se efectuara y mientras tanto los encomenderos aprovechaban para exigir a las comunidades diversos productos o mano de obra para minas, haciendas y servicios domésticos, en un sistema condenado por las Leyes pero extendido por todas partes, conocido con el nombre de servicios personales.

Las comunidades no fueron entes pasivos que accedían sin protestar a las exigencias de los conquistadores. Mediante negociaciones que muy seguramente se dieron durante los primeros meses de la conquista, los caciques acordaron con los españoles unas cantidades de productos o de trabajadores para las empresas agrícolas o mineras. En Pamplona lo común era que cada comunidad entregara de 10 a 20 hombres para el trabajo en las minas y le hiciera labranzas de trigo y maíz al encomendero. Eventualmente entregaban productos como mantas, pescado o bija, en cantidades que dependían del número de familias que tuviera la comunidad. Muy posiblemente estos productos y este pago del tributo en forma de trabajo tenían que ver con costumbres ancestrales de los indígenas, quienes hacían lo mismo con sus caciques antes de la llegada de los españoles.

Un hecho curioso que se presenta al analizar la Visita de 1559 es que una parte de las comunidades todavía no tributaba. Si observamos la Tabla $\mathrm{N}^{\circ}$ 1 , vemos que cerca del $11 \%$ de las encomiendas declararon que no daban nada al encomendero: 
TABLA N 1 . ENCOMIENDAS Y TRIBUTOS EN 1559

\begin{tabular}{|lcc|}
\hline \multicolumn{1}{|c}{ VISITA DE 1559 } & TOTAL & PORCENTAJE \\
Encomiendas que no dan tributo. & $\mathbf{1 3}$ & $11.11 \%$ \\
\cline { 2 - 3 } Encomiendas que tributan. & $\mathbf{1 0 4}$ & $88.89 \%$ \\
TOTAL & 117 & $100.00 \%$ \\
\hline
\end{tabular}

Fuente: Visita de Cristóbal Bueno (1559), A.G.N. (Santafé de Bogotá), Visitas de Santander, t. 3, ff. 709r-881v.

Se trataba en su mayoría de encomiendas situadas en las tierras bajas del norte de la provincia, en los valles ya mencionados de Táchira y Arboledas, donde el dominio español aún no se había asentado de manera estable después de 10 años de fundada la ciudad de Pamplona. Algunas declararon que "aún no habían dado la paz", otras se habían rebelado y huido adentrándose en los bosques y otras finalmente acababan de "dar la paz" y por este motivo todavía no les exigían el pago de tributos.

Otras comunidades de la misma región, como los Chitaguaos de Gutierre de Oruña, declararon que acababan de "dar la paz" y por esta razón no daban indios para las minas, sino que solamente le hacían algunas labranzas al encomendero. En esa ocasión se presentaron 7 capitanes ante el Visitador, pero no llevaron toda su gente "para no alterarlos". Además contaron que otro capitán llamado Suratacoche no había querido asistir a la Visita por estar rebelado con toda su gente. ${ }^{17}$

Las comunidades recién sometidas no tributaban, pero a medida que el dominio se iba afianzando empezaban a hacer labranzas para el encomendero. Durante algún tiempo esto era todo lo que les pedían. Los españoles usaban evidentemente la fuerza para someterlas, pero también combinaban otros métodos para atraerlas de manera no violenta. Estas comunidades de la periferia de la provincia, que en la mayoría de los casos no tenían una organización de cacicazgos fuertes eran difíciles de someter, y se fragmentaban con facilidad en grupos más pequeños a ordenes de capita-

${ }^{17}$ Visita de Cristóbal Bueno (1559), f. 786v. 
nes que conocían la zona y se adentraban en el bosque, manteniendo unas pautas de asentamiento semi-nómadas. Los españoles, por lo tanto no podían utilizar una fuerza excesiva con ellos, porque corrían el riesgo de que se fugaran.

Por algunos datos tomados de Visitas posteriores referentes a algunas comunidades de indios Gemarás (posiblemente de filiación Tuneba), sabemos que en algunos casos eran atraídos con regalos para sacarlos de sus tierras y poblarlos en sitios cercanos a las minas y las haciendas. En 1602, ciertos indios Gemarás fueron poblados en el Valle de Los Locos o Labateca), donde les daban mantas y carne para que no regresaran a su "ugar de origen. El capitán de la comunidad declaró en esa ocasión que el encomendero les regalaba "mantas chiquitas", sal y les mataba ganado de vez en cuando, para que tuvieran "buen corazón" con él. Por aquel entonces aún no sabían el idioma ni la doctrina. En palabras del cura del lugar, eran bastante "chontales" y "chapetones" y estaban poco "industriados". Unos años después, cuando ya se habían acostumbrado a la nueva vida, fueron llevados como trabajadores a las minas. ${ }^{18}$

\section{El sistema de tributos}

\section{a) Servicios personales: minas y labranzas}

En la mayoría de los pueblos visitados en 1559, los caciques declararon que daban como tributo algunos indios para las minas, hacían labranzas para el encomendero y le servían en otra serie de actividades como pajes, cargadores o en oficios domésticos. Las labranzas eran realizadas en tierras que seguían siendo propiedad de la comunidad, pero cuyo producto era entregado al encomendero. Este, a su vez, utilizaba estos productos para alimentar a los trabajadores de las minas, para pagar a los criados y sirvien-tes, o para venderlos en los mercados locales.

En 1560, el autor de una Relación anónima informaba a la Corona española que los indios de Pamplona realizaban para los encomenderos, una serie de labores que incluían entre otras cosas:

${ }_{18}$ Visita de Beltrán de Guevara (1602), Visitas de Santander, t. 3, ff. 681 v-692v. 
"...dalles muchachos para que saquen oro en las minas e hazerle sus casas en la cibdad, de paja y algunas ay ya de tapias, guardanle sus ganados, hazenles sus simenteras de trigo y mahiz y cebada y papas y cogenlas y metenlas en casa de sus encomenderos"19

Según este informe, los naturales de la provincia eran gente "desnuda y mísera", que no tenían más "granjerias" que sus propias sementeras y algunas mantas que elaboraban con el poco algodón que se cogía en algunos sitios. Por eso, a pesar de que las leyes prohibían los servicios personales, consideraba que lo mejor era no establecer por ahora tributos en especie. Se utilizaba de esta manera un argumento que sería recurrente en las Visitas que siguieron hasta llegar al siglo XVII.

Como se puede observar, casi el 50\% de las encomiendas tributaban haciendo las labranzas del encomendero y dando indios para las minas. Un $20 \%$ entregaban además de ésto algunas mantas y un 11\% le hacían solamente sus labranzas. El resto de las encomiendas, es decir un 19\%, aproximadamente, ofrecían productos variados como bija, cera, miel, pescado y venados, además de las mantas y el trabajo en las labranzas y en las minas.

En el pueblo de Bochalema, por ejemplo, el cacique declaró que daban como tributo al encomendero Alonso Carrillo los 25 indios que estaban con sus familias sacando oro de las minas y además le hacían unas labranzas de trigo y de maíz. El producto era luego transportado hasta las minas para alimentar a los trabajadores. ${ }^{20}$ Los indios de Operoma, del mismo encomendero, le daban 16 muchachos para las minas y también le hacían algunas labranzas. ${ }^{21}$ El cacique de Silos, por su parte, declaró con granos de maíz que daba 26 trabajadores para las minas de Luis Jurado, junto con el cuidado de las labranzas y algunos sirvientes para su casa. ${ }^{22}$

En la Tabla $\mathrm{N}^{\circ} 2$ presentamos las formas más frecuentes del tributo en las encomiendas visitadas en 1559 por Cristóbal Bueno:

\footnotetext{
19 "Relación Anónima de 1560", Hermes Tovar (Transcripción e Introducción), No hay Caciques ni Señores. Barcelona, Editorial Sendai, 1988, p. 97.

20 Visita de Cristóbal Bueno (1559), f. 744v.

${ }^{21}$ Ibid, f. 743r.

22 Ibid, f. 737r.
} 


\section{TABLA No ${ }^{\circ}$ 2. FORMAS DEL TRIBUTO EN LA PROVINCIA DE PAMPLONA EN 1559}

\begin{tabular}{|c|c|c|}
\hline $\begin{array}{r}\mathrm{C} / \\
\mathrm{ENC}\end{array}$ & $\begin{array}{l}\text { INTIDAD } \\
\text { OMIENDAS }\end{array}$ & PORCENTAJE \\
\hline No dan tributos por no haber dado la paz & 2 & 1.71 \\
\hline No dan tributos por estar rebelados & 5 & 4.27 \\
\hline No dan tributos porque acaban de dar la paz & 6 & 5.13 \\
\hline Están rebelados pero dan indios para las minas & 1 & 0.85 \\
\hline Labranzas & 13 & 11.11 \\
\hline Labranzas y mineros & 57 & 48.72 \\
\hline Labranzas, mineros y oro & 2 & 1.71 \\
\hline Labranzas, mineros y bija & 2 & 1.71 \\
\hline Labranzas, mineros y mantas & 24 & 20.51 \\
\hline Labranzas, mineros, mantas y bija & 2 & 1.71 \\
\hline Labranzas, mineros, mantas y cueros de venado & 1 & 0.85 \\
\hline Labranzas, mineros, mantas y cera & 1 & 0.85 \\
\hline $\begin{array}{l}\text { Labranzas, mineros, mantas, cera, miel, } \\
\text { pescado y venados }\end{array}$ & 1 & 0.85 \\
\hline TOTAL & 117 & 100.00 \\
\hline
\end{tabular}

Fuente: Visita de Cristóbal Bueno (1559), A.G.N. (Santafé de Bogotá), Visitas de Santander, t. 3, ff. 709r-881v.

El panorama no cambió mucho en el año que transcurrió hasta la visita del Oidor Tomás López. En mayo de 1560, fue enviado por la Corona este nuevo Visitador, miembro de la Real Audiencia, con el fin de aplicar las Nuevas Leyes, prohibir el trabajo de los indios en las minas, congregarlos en pueblos al estilo español y, sobre todo, realizar la tasación de tributos para evitar que los encomenderos les siguieran exigiendo servicios personales.

El Oidor recorrió la región, interrogó a los caciques y dio una serie de órdenes que nunca se cumplieron. Como la mayoría de los expedientes se han perdido, se ignora si el funcionario tasó los tributos en la provincia, aunque 
él mismo declaró en el Juicio de Residencia que se le siguió en 1562 que en Pamplona había prohibido el trabajo en las minas del Río del Oro y había tasado los tributos, pero después ninguna autoridad local se preocupó por poner en práctica sus órdenes. ${ }^{23}$

La información que se ha conservado de esta Visita corresponde a unas 20 encomiendas y se encuentra muy dispersa en varios fondos del Archivo General de la Nación. La mayoría de los pueblos fueron inspeccionados entre abril y mayo de 1560, algunos meses después de la epidemia de viruelas. En casi todos, los caciques e indios principales que declararon ante el Oidor dijeron que "antes de las viruelas" solían enviar algunos indios a las minas como tributo al encomendero, pero que después, y debido a las muertes causadas por la enfermedad, no habían vuelto a enviar a nadie.

Como se observa en la tabla $N^{\circ} 3$, en ese año la forma más frecuente del tributo (cerca del $58 \%$ de las encomiendas) fue el trabajo en las labranzas del encomendero. Pero en contraste con lo declarado en el año anterior ante Cristóbal Bueno, esta vez solamente el 17\% de los caciques reconocieron que daban indios para las minas a la vez que hacían estas labranzas.

En el pueblo de Chirivita (o Servitá), encomendado a Simón del Basto, el cacique Chirivita y el capitán Saba declararon que antes de la epidemia solían enviar unos 20 indios al Río del Oro, pero que después ya no lo hacían. Ahora sólo le daban al encomendero algunos venados y le hacían labranzas de trigo y de maíz. ${ }^{24}$ En el pueblo de Inegavita, encomienda de Juan Pérez, el cacique Cualaba contó que antes de las viruelas iban algunos indios a las minas, pero que ahora ya no. Además de esto solían darle cada año una manta por cada indio casado, es decir, unas 20, y le hacían sus labranzas. ${ }^{25}$ En otros lugares, además de las labranzas se entregaban pescados, venados, trigo, turmas, cebada y bija, que era apreciada como tinte y condimento por los indios.

\footnotetext{
${ }^{23}$ Sobre los motivos y resultados de la Visita realizada en el Nuevo Reino de Granada por el Oidor Tomás López se puede consultar: Tomás López, Colonización de América. Informes y Testimonios, (Compilado por Luciano Pereña, C. Baciero y F. Maseda), Madrid, Consejo Superior de Investigaciones Científicas, 1990, p. 231.

${ }^{25}$ Visita de Tomás López (1560), Miscelánea, t. 94, ff. 344-349.

${ }^{26}$ Ibid, t. 85, ff. 955-958.
} 
TABLA Nº 3. FORMAS DEL TRIBUTO EN 1560

\begin{tabular}{|c|c|c|}
\hline TRIBUTOS & ENCOMIENDAS & PORCENTAJE \\
\hline Labranzas & 15 & $60 \%$ \\
\hline Labranzas y mineros & 4 & $16 \%$ \\
\hline Labranzas y mantas & 1 & $4 \%$ \\
\hline Labranzas, mantas, mineros y bija & 1 & $4 \%$ \\
\hline Labranzas, mantas y bija & 1 & $4 \%$ \\
\hline Labranzas y pescado & 1 & $4 \%$ \\
\hline Labranzas y venados & 1 & $4 \%$ \\
\hline TOTAL & 24 & $96 \%$ \\
\hline
\end{tabular}

Fuente: Visita de Tomás López, A.G.N. (Santafé de Bogotá), Caciques e Indios, t. 32, ff. 638r-644v y t. 46, ff. 164r-169v; Miscelánea, t. 15, ff. 916r-923v; t. 57, ff. 912r-923v; t. 77, ff. 214r-218v, 325r-329v y 898r-903v; t. 85, ff. 954r-959v, y t. 94, ff. 344r-349v; Visitas de Santander, t. 9. ff. 944r-959v y 1005r-1020v.

Cuando el Oidor interrogó a los españoles sobre las razones que tenían para enviar a los indios a las minas como una forma de tributo, violando las Leyes Nuevas, Juan Ramírez, encomendero de Zule señaló que:

" ... como los indios de esta tierra son pobres, que no tienen nada que dar, y tienen las minas de oro en su propia tierra, algunas veces los caciques y principales le han dado a este testigo algunos muchachos para sacar oro..." 26

Acto seguido, confesó tener un grupo de unos 25 muchachos trabajando para él. Pero su ejemplo de franqueza no fue seguido por los demás encomenderos, ya que la mayoría negó los cargos que se les levantaron o se disculparon diciendo que los indios iban a las minas por su propia voluntad, aunque "después de las viruelas" no habían vuelto a trabajar.

26 Ibid,t.15,f.918r. 
La situación señalada por los caciques de que ya no iban trabajadores a las minas por causa de las viruelas pudo ser una respuesta forzada por los encomenderos para que no los denunciaran, o bien pudo ser una situación real, pero transitoria. Si las declaraciones eran ciertas, la epidemia seguramente había obligado a detener por unos meses las labores mineras, con el fin de que los enfermos se recuperaran, y fue en este lapso que el Visitador Tomás López llegó a la región. Lo cierto es que las labores pronto se reanudaron, ya que las minas nunca cesaron de trabajarse con mano de obra indígena durante todo el resto del siglo XVI.

\section{b) Los productos: mantas, bija, oro y animales}

Si analizamos los productos que daban a sus encomenderos los indios de la región en los años de 1559-1560 se puede apreciar que no eran muy variados. Atrás hemos visto que la mayoría de los encomenderos se conformaban con el trabajo de sus indios en las minas y labranzas, lo cual les proporcionaba oro y productos para el consumo y la comercialización. Sin embargo en una tercera parte de las encomiendas, además de esto se pedía a los indios una serie de productos como algunos pesos de oro, cueros de venado, pescados y especialmente bija y mantas. Estos bienes eran recogidos anualmente, de acuerdo con cuotas variables, fijadas por el encomendero.

En este año cerca del $28 \%$ de las encomiendas declararon dar mantas, que en ocasiones no se entregaban solas, sino acompañadas por bija, cera, miel, cueros de venado y pescado. La producción de mantas no era generalizada y se concentraba solamente en dos grandes zonas, que muy seguramente se habían especializado en la elaboración de textiles desde tiempos prehispánicos. Estas zonas son los valles de Labateca (o Valle de los Locos) e Ima, hacia el suroriente de la provincia, cerca de la zona de frontera con los Tunebos de los Llanos Orientales, y los Valles de Guaca y Servitá, al suroccidente de la provincia, en la zona de frontera con los Guane. El Valle de Servitá, además, representa la única zona donde los indios mencionan el pescado y los cueros de venado como parte del tributo. En total, los encomenderos recibían al año unas 800 mantas de las comunidades de la provincia, elaboradas en su mayoría por las mujeres. 
TABLA N 4. GENEROS QUE COMPONEN LOS TRIBUTOS EN 1559

\begin{tabular}{|lcc|}
\hline \multicolumn{1}{|c}{ GENEROS } & $\begin{array}{c}\text { ENCOMIENDAS } \\
\text { QUE LOS DAN }\end{array}$ & $\begin{array}{c}\text { PORCENTAJE SOBRE TOTAL DE } \\
\text { ENCOMIENDAS QUE TRIBUTAN }\end{array}$ \\
Labranzas & 103 & $99.0 \%$ \\
Indios Mineros & 91 & $87.5 \%$ \\
Mantas & 29 & $27.8 \%$ \\
Bija & 4 & $3.8 \%$ \\
Oro & 2 & $1.9 \%$ \\
Venados & 2 & $1.9 \%$ \\
Cera & 2 & $1.9 \%$ \\
Miel & 1 & $0.9 \%$ \\
Pescado & 1 & $0.9 \%$ \\
\hline
\end{tabular}

Fuente: Visita de Cristóbal Bueno (1559), A.G.N. (Santafé de Bogotá), Visitas de Santander, t. 3, ff. 709r-881v.

La bija representaba el segundo producto en importancia después de las mantas, aunque solamente un $3 \%$ de las encomiendas lo daban como tributo. Se entregaba en forma de pequeños "panes" (de 50 a 60 al año), de un tinte rojo natural preparado con ciertas plantas, se usaba para pintar el cuerpo, las telas e incluso como condimento. Entre los indios era bastante apreciada y su comercio estaba ampliamente difundido en tiempos prehispánicos. Según el cronista Pedro de Aguado, la bija era considerada también como una especie de moneda entre los Chitareros. ${ }^{27}$

Dos comunidades daban oro en polvo al encomendero. Se trataba de Chiscuta de Miguel de Tiebas y Leuta ("Reuta" o Tabarata) de Pedro Quintero, las cuales además de los trabajadores para las minas y las labranzas tenían que entregar 50 pesos de oro al año. ${ }^{28}$ Sin embargo, estos fueron casos excepcionales, que sólo representaban el 2.1\% del total. La misma proporción se presentó en los venados y la cera, mientras que solamente una encomienda,

${ }^{27}$ Fray Pedro de Aguado, Recopilación, t.2, p. $461 .{ }^{28}$

Visita de Cristóbal Bueno (1559), ff. 757v y 79 lv. 
compuesta por los pueblos de Servitá y Valegrá, declaró que daba algo de miel y pescados. ${ }^{29}$

Estos productos tenían un escaso valor para los españoles, quienes preferían el oro, el trigo o la cebada. Ni las mantas, ni la bija, eran consumidos habitualmente por las élites blancas, quienes por lo general conseguían telas importadas desde Europa por los mercaderes asentados en la ciudad. Con el oro de las minas compraban ropa, licores, muebles y otra serie de mercancías que enriquecieron a algunos comerciantes. ${ }^{30}$ Por lo tanto, las mantas eran usadas por los encomenderos para pagar los servicios de los mismos indios, los mestizos o los blancos pobres o para vestir a los mineros de sus cuadrillas. En las Visitas posteriores a las minas y las encomiendas, los indios declararon que los encomenderos solían recompensarlos con algunas mantas, carne de venado, cuentas de collar, espejos y otras baratijas por sus servicios. También los favores de los Caciques eran recompensados con mantas y otras cosas por los españoles. ${ }^{31}$

En la Visita de 1560 la tendencia señalada es similar, aunque, como ya se dijo, los datos son muy fragmentarios. Al observar la Tabla $\mathrm{N}^{\circ} 5$, se aprecia que los productos y la cantidad de encomiendas que los dan mantienen más o menos las mismas características de la Visita del año anterior. Este hecho no es de extrañar, ya que en tan corto tiempo es muy difícil que se hubieran producido cambios significativos, fuera de la baja sensible en el número de trabajadores que iban a las minas que ya hemos analizado.

En los lugares donde los caciques dieron cifras de los productos que entregaban al encomendero, se dijo que la cuota era más o menos de una manta por cada indio varón al año. Por ejemplo, en la encomienda de Ima de Juan Pérez, el cacique Manachagua dijo que en su pueblo se producía algodón para hacer mantas. Cada indio entregaba una al año, junto con algo de bija y hacían dos labranzas en las que todos trabajaban. En Inegavita, del mismo encomendero, el Cacique Cualaba también declaró que daban entre 20

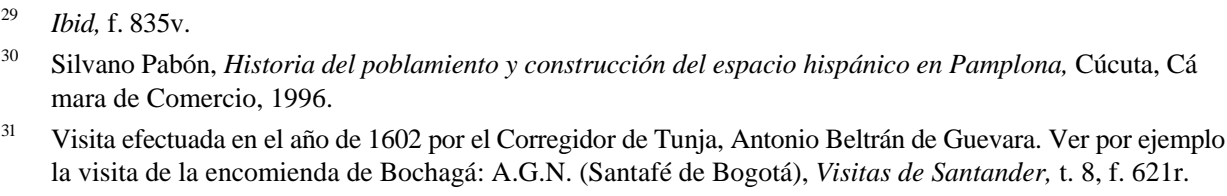

31 Visita efectuada en el año de 1602 por el Corregidor de Tunja, Antonio Beltrán de Guevara. Ver por ejemplo la visita de la encomienda de Bochagá: A.G.N. (Santafé de Bogotá), Visitas de Santander, t. 8, f. 621r. 
y 30 mantas de algodón anuales, además de los trabajadores para las minas y las labranzas. ${ }^{32}$

TABLA N ${ }^{\circ}$ 5. GENEROS QUE COMPONEN LOS TRIBUTOS EN 1560

\begin{tabular}{|lcc|}
\hline & $\begin{array}{c}\text { ENCOMIENDAS QUE DAN } \\
\text { ESTOS GENEROS }\end{array}$ & PORCENTAJE \\
Labranzas & 24 & \\
Indios mineros & 6 & $96 \%$ \\
Mantas & 3 & $24 \%$ \\
Bija & 2 & $12 \%$ \\
Pescado & 1 & $8 \%$ \\
Venados & 1 & $4 \%$ \\
\hline
\end{tabular}

Fuente: Visita de Tomás López, A.G.N. (Santafé de Bogotá), Caciques e Indios, t. 32, ff. 638r-644v y t. 46, ff. 164r-169v; Miscelánea, t. 15, ff. 916r-923v; t. 57, ff. 912r-923v; t. 77, ff. 214r-218v, 325r-329v y 898r-903v; t. 85, ff. 954r-959v, y t. 94, ff. 344r-349v; Visitas de Santander, t. 9, ff. 944r-959v y 1005r-1020v.

La Relación Anónima enviada a España en 1560 nos permite hacer una comparación entre la situación de la Provincia de Pamplona y el resto de la Nueva Granada en materia de tributos. En la Tabla $N^{\circ} 6$ podemos comparar el volumen de los tributos con respecto al resto de la Nueva Granada. Aunque las cifras pueden contener bastantes errores debido a múltiples factores, sirven de todas maneras para tener una idea aproximada de la situación.

Se aprecia en primer lugar que la Provincia de Pamplona es una de las que más pueblos de indios tiene, ocupando junto a Tunja el primer lugar con unas 110 encomiendas registradas. Demográficamente ocupa el tercer lugar, después de Tunja y Santa Fé, aunque la cifra que se cita en esta relación (20.130 indios) es bastante dudosa, teniendo en cuenta que autores como Germán Colmenares y Hermes Tovar han calculado una población superior a los 30.000 habitantes en 1559, con base en la Visita de Cristóbal Bueno. $^{33}$

32 Visita de Tomás López (1560), Miscelánea, t. 85, ff. 954-958.

33 Germán Colmenares, Encomienda y Población en la Provincia de Pamplona (1559-1650), Bogotá, Universidad de los Andes, 1969 y Hermes Tovar Pinzón, "Estado Actual de los Estudios de Demografía Histórica en Colombia", Anuario Colombiano de Historia Social y de la Cultura, N 5, Bogotá, Universidad Nacional de Colombia, 1970, pp. 65-140. 
Se observa también que en Pamplona, Ibagué, Mariquita y Tocaima la forma predominante del tributo es entregar indios para las minas, siendo Pamplona el lugar donde se dan más trabajadores (unos 1.500). En Santa Fé, Tunja y Vélez los indios se encuentran tasados en mantas, oro y productos del campo. En Pamplona se entregan mantas sin que exista una tasa fija, de acuerdo al arreglo que se tenga con cada comunidad. A nivel de las mantas se aprecia que Pamplona ocupa el último lugar con sólo 527 mantas al año, siendo Tunja y Santa Fé las principales productoras con unas 34.000 y 10.000 mantas, respectivamente. Estas mantas eran bastante apreciadas en el resto de provincias, incluyendo aquellas que también producían textiles, como Vélez y Pamplona, donde los indios incluso las preferían a las propias, por considerarlas de mejor calidad.

\section{TABLA ${ }^{\circ}$ 6. TASA DE LOS INDIOS ENCOMENDADOS} EN LA NUEVA GRANADA EN 1560

\begin{tabular}{|c|c|c|c|c|c|c|c|}
\hline PUEBLOS & VECINOS & $\begin{array}{l}\text { PUEBLOS } \\
\text { DE INDIOS } \\
\text { (ENCOMIEN } \\
\text { DAS) }\end{array}$ & $\begin{array}{c}\text { NUMERO } \\
\text { DE } \\
\text { INDIOS }\end{array}$ & $\begin{array}{l}\text { INDIOS } \\
\text { DE } \\
\text { LAS } \\
\text { MINAS }\end{array}$ & $\begin{array}{l}\text { TASA EN } \\
\text { MANTAS }\end{array}$ & $\begin{array}{l}\text { TASA } \\
\text { DE } \\
\text { ORO }\end{array}$ & $\begin{array}{l}\text { FANEGAS } \\
\text { DE } \\
\text { SEMBRA- } \\
\text { DURA }\end{array}$ \\
\hline Santa Fé & 55 & 57 & 36.552 & & 9.772 & 9.241 & 1.548 \\
\hline Tunja & 73 & 110 & 52.647 & & 33.726 & 13.511 & 1.933 \\
\hline Vélez & 38 & 74 & 14.679 & & 4.147 & 3.870 & 620 \\
\hline Pamplona & 57 & 110 & 20.1301 & .465 & 527 & & \\
\hline Ibagué & 27 & 36 & 2.701 & 500 & & & \\
\hline Mariquita & 23 & 36 & 2.038 & 400 & & & \\
\hline Tocaima & 31 & 59 & 3.201 & 625 & & & \\
\hline San Juan & 40 & & & & & & \\
\hline Victoria & 80 & & & & & & \\
\hline Mérida & 40 & & & & & & \\
\hline TOTALES & 464 & 482 & 13.1948 & 2.990 & 48.172 & 26.622 & 4.101 \\
\hline
\end{tabular}

Fuente: tomado y adaptado de la "Visita de 1560". Hermes Tovar (Transcripción), No Hay Caciques Ni Señores, Barcelona, Editorial Sendai, 1988, p. 119. 


\section{Evolución de los sistemas de trabajo a lo largo del siglo XVI}

\section{a) El trabajo en las minas}

Cuando fueron descubiertas en 1551 las minas del Río del Oro y de los Páramos, los españoles llevaron indios para explotarlas pero tuvieron que enseñarles técnicas de mazamorreo y de perforación de socavones, que se usaban en el Perú y otras regiones, ya que los Chitareros no trabajaron minas de oro en tiempos prehispánicos. ${ }^{34}$

La cantidad de indios que eran enviados a las labores mineras por comunidad variaba en los primeros años de 10 a 50 individuos, dependiendo del tamaño del pueblo. Los Caciques pactaron con cada uno de los encomenderos la cantidad de hombres que irían a las minas, tratando muy seguramente de regatear al máximo, aprovechando que los españoles aún no tenían una idea exacta de cuanta gente había.

Al momento de la fundación de la ciudad en 1549 y el posterior descubrimiento de las minas de oro en 1551 se encontraba terminantemente prohibido que los indios fueran enviados a trabajar en las minas. Las Leyes Nuevas de 1542 y una Cédula Real de 1549 habían establecido que bajo ninguna circunstancia podían ser enviados a las minas, aunque lo hicieran por su propia voluntad. De hecho, en los títulos de encomienda se consignaban siempre estas disposiciones y se le advertía a los encomenderos que corrían el riesgo de perder sus indios si no acataban las órdenes del Rey.

Esto no fue obstáculo para los encomenderos de Pamplona. En 1559 se contaron unos 1.600 trabajadores en las minas, sin tener en cuenta sus mujeres e hijos. Esta cantidad de personas representaba una proporción del $18 \%$ de la población masculina económicamente activa. ${ }^{35}$ Estos trabajadores eran organizados en cuadrillas de acuerdo a su lugar de origen y colocados bajo las órdenes de un "minero" o capataz. Luego eran conducidos a los páramos de Vetas y Suratá donde se explotaban minas de socavón o a las tierras bajas del Río del Oro (cerca de la actual ciudad de Bucaramanga),

\footnotetext{
${ }^{34}$ Fray Pedro Aguado, Recopilación, t. 2, p. 461.

${ }^{35}$ Hermes Tovar Pinzón, "Estado Actual de los Estudios..." Anuario, p. 102.
} 
donde el metal bajaba desde los páramos arrastrado por quebradas y riachuelos y se explotaba lavando las arenas en minas de aluvión. Cada indio de la cuadrilla tenía que entregar una cuota semanal, que más o menos se situaba alrededor de un peso de oro en polvo, llamada "jornal". En lugares como el Río del Oro, el jornal era recogido por los capataces los domingos y si los indios no cumplían se exponían a fuertes castigos. ${ }^{36}$

Los Jueces y Visitadores enviados por la Corona española para evitar que los indios fueran conducidos a las minas constataron desde épocas muy tempranas que las Leyes Nuevas se estaban violando sistemáticamente. En diciembre de 1551, unos meses después del descubrimiento de las minas, un Juez Visitador llegó a las rancherías recién organizadas en los páramos y ordenó que los indios retornaran a sus pueblos de origen. Sin embargo los encomenderos hicieron caso omiso, alegando que no tenían dinero para comprar esclavos como lo mandaba la Cédula de 1549 y que los indios trabajaban voluntariamente. A raíz de la Visita enviaron un extenso memorial al Rey pidiendo revocar las Leyes, pues de lo contrario la ciudad se despoblaría. ${ }^{37}$

Lo mismo sucedió durante la Visita de Tomás López en 1560. Las indicaciones dadas por el Oidor para que los indios no fueran enviados a las minas generaron incluso una airada protesta de los encomenderos, quienes convocaron un cabildo abierto y decidieron enviar un procurador hasta España para presentar sus quejas a la Corona. Argumentaban que en aquellas tierras era inevitable utilizar indios en las labores mineras, ya que los negros eran muy costosos. Además sostenían que los indios eran bien tratados, bien pagados y trabajaban voluntariamente. De cumplirse al pie de la letra las Leyes Nuevas, lo único que se lograría sería despoblar aquellas tierras porque sin el oro de las minas los españoles no tendrían ningún atractivo para permanecer en ellas. $^{38}$

36 Jorge Gamboa, "El Trabajo de los Indios en las Minas de Pamplona", Poblamiento Regional, Etnohistoria y Etnografía en Pamplona. Memorias del I Simposio de Historia Regional "Pamplona 445 años", Cúcuta, Cámara de Comercio, 1995, pp. 165-200.

37 Juan Friede (Transcripción), Fuentes Documentales para la Historia del Nuevo Reino de Granada desde la instalación de la Real Audiencia de Santafé, t. 1, Bogotá, Biblioteca Banco Popular, 1975, p. 191.

38 Acta del Cabildo de la Ciudad de Pamplona del 21 de mayo de 1560. Primer Libro de Actas del Cabildo de la Ciudad de Pamplona en la Nueva Granada 1552-1561, Dirección, prólogo e índice razonado por Enrique Otero D'Costa, Bogotá, Academia de Historia Colombiana, 1950, p. 312. 
Las presiones de los encomenderos americanos llevaron a que finalmente el Rey Felipe II permitiera en 1568 el trabajo de los indios en las minas, pero bajo la condición de que lo hicieran voluntariamente y a cambio de un salario justo. Los indios debían ser contratados mediante un "concierto", firmado ante las autoridades, quienes se encargarían de hacer pagar los salarios. Pero estos mandatos tampoco se cumplieron y los indios de la Provincia de Pamplona siguieron sometidos al sistema del "jornal". Eventualmente se les daban algunas mantas, camisetas, sal y otras cosas como pago por sus servicios, tal como lo declararon en 1572 los indios de la encomienda de Panaga. ${ }^{39}$

En las Visitas practicadas durante el siglo XVI los indios por lo general decían que se encontraban en las minas por su propia voluntad y "de corazón". Ellos mismos alegaban ante los Visitadores que debido a su "pobreza" no deseaban dar tributo y preferían dar algunos muchachos para las minas. Así lo hicieron en 1572 los indios de la parcialidad de Arola, de la encomienda de Panaga de Alonso de Parada. El Cacique Tutepa declaró en esa ocasión que el encomendero tenía algunos negros, con los cuales iban 9 indios a sacar oro. Con el oro que le entregaban, su amo les compraba mantas, sal, camisetas y otras cosas. También le pagaba al Cacique por su trabajo. ${ }^{40}$

Los indios mineros que fueron llevados ante el Visitador agregaron que en años anteriores había muchos en las minas, pero que ya se habían muerto la mayoría. De los 9 que iban con los negros, solamente 4 sabían "lavar" oro. Los demás eran algo "chapetones" y como no sabían el oficio, desmontaban la tierra y la piedra en donde lo sacaban. Al ser llamado Alonso de Parada para que explicara por qué mandaba a sus indios a buscar oro, se disculpó alegando que ellos iban por su propia voluntad y porque les daba ropa y comida. También les enseñaba la doctrina y los curaba en sus enfermedades. Esta clase de disculpas eran comunes en las Visitas y dejan siempre la impresión de que los indios eran previamente aleccionados acerca de lo que debían responder ante los jueces para que los encomenderos no fueran sancionados.

El Visitador Juan Suárez de Cepeda reunió de todas maneras a los indios del Río del Oro y les manifestó sus derechos y obligaciones en abril de

39 A.G.N. (Santafé de Bogotá), Caciques e Indios, t. 32, f. 362r ${ }^{40}$

Ibid, f. 364r. 
1572. El trabajo en las minas había sido permitido desde 1568, pero bajo la condición de que fuera voluntario y a cambio de un salario. Tampoco podían llevar gente a trabajar en climas distintos a los de sus pueblos de origen, lo cual era frecuente en el Río del Oro, donde la mayoría de las cuadrillas presentes provenían de climas fríos o templados, muy distintos al calor que allí reinaba. Por esta razón, el Visitador dispuso regresarlos a sus pueblos, aunque esta orden, como todas las anteriores que se dieron en el mismo sentido, tampoco fue cumplida. ${ }^{41}$

Para finales del siglo XVI los tres poblados que habían surgido a raíz de las actividades mineras se habían consolidado con una población más o menos permanente. Las cuadrillas eran mantenidas por los encomenderos trayendo nuevos indios a medida que se morían o se fugaban. En los páramos surgieron los Reales de minas de Vetas y La Montuosa, cerca del poblado indígena de Suratá. En las tierras bajas y calurosas regadas por una multitud de quebradas, surgió el Real de minas del Río del Oro, en tierras ocupadas por los indios de la encomienda de Bucarica, que luego darían origen al pueblo de Bucaramanga. El censo más antiguo que conocemos se realizó durante la Visita del Corregidor de Tunja, don Antonio Beltrán de Guevara en 1602. En la tabla $N^{\circ} 7$ se puede apreciar la población que tenía cada uno, 50 años después de iniciadas las labores mineras.

\section{TABLA N ${ }^{\circ}$ 7. POBLACION INDIGENA EN LOS REALES DE MINAS DE PAMPLONA EN 1602}

\begin{tabular}{|lrrrrr|}
\hline REAL DE MINAS & $\begin{array}{c}\text { INDIOS } \\
\text { ITIIES }\end{array}$ & CHUSMA & $\begin{array}{c}\text { RESER- } \\
\text { VADOS }\end{array}$ & ALSENTES & TOTAL \\
Vetas & 276 & 395 & 20 & 0 & 691 \\
La Montuosa (Suratá) & 66 & 85 & 0 & 0 & 151 \\
Río del Oro (Bucaramanga) & 59 & 137 & 3 & 5 & 204 \\
TOTAL & 401 & 617 & 23 & 5 & 1046 \\
\hline
\end{tabular}

Fuente: A.G.N. (Santafé de Bogotá), Visitas de Santander, t. 5. f. 228 y siguientes y t. 11, ff 998 y siguientes. Visitas de Boy acá, t. 6, f. 749 y siguientes.

41 Visita de Juan Suárez de Cepeda al Río del Oro (1572) A.G.N. (Santafé de Bogotá), Caciques e Indios, t. 32, ff. 269r-273r.

${ }^{42}$ La clasificación de la población se hace de acuerdo a las categorías en que fueron agrupados por las autoridades coloniales en el censo: Indios útiles: Hombres de 17 a 54 años, que deben pagar tributo. Chusma: Mujeres y niños. Reservados: Hombres mayores de 54 años, inválidos o personas exentas del pago de tributo. 
La Visita del Corregidor de Tunja en 1602 arrojó un total de 2.711 indios útiles (hombres económicamente activos) en toda la Provincia, lo cual significaría que un $14,7 \%$ de ellos estaban en las minas. ${ }^{43}$ Esta proporción había bajado un poco con respecto a la proporción del 18\% existente en 1559. Esto confirma el hecho señalado por los cronistas y por las declaraciones de los indios en las Visitas realizadas después de 1560, acerca de la corta duración de los primeros y fabulosos descubrimientos auríferos. Después de algunos años en que se lograron grandes ganancias con cientos de trabajadores, se presentó una rápida decadencia de las labores. El agotamiento de las vetas auríferas superficiales y la disminución de la mano de obra indígena debido a las duras condiciones de trabajo y las epidemias, determinó la crisis de la minería del oro, que se prolongó a lo largo de todo el siglo XVII.

\section{b) El trabajo en el campo}

Mientras los hombres seleccionados por los encomenderos iban a las minas con sus familias, la mayor parte de los indígenas de la Provincia de Pamplona permanecía en sus pueblos, dedicada a las labores del campo. De esta población, Colmenares ha calculado que del 20 al 60\% de los hombres en edad de trabajar eran empleados por el encomendero en sus tierras, mientras los demás atendían los cultivos y granjerias de la comunidad. Por eso los indios se quejaban constantemente de que no les quedaba tiempo para hacer sus propias labranzas de maíz, en las cuales debían colaborar cada vez con más frecuencia las mujeres, los niños y los ancianos. A esto se le sumaba el hecho de que los encomenderos comenzaron a apoderarse de algunas tierras fértiles donde sembraron trigo y caña de azúcar. ${ }^{44}$

Los indios permanecían durante toda la semana bajo las órdenes de mayordomos o capataces, trabajando incluso algunos días de fiesta, con lo cual no les quedaba tiempo para atender sus propios cultivos, ni podían asistir a la doctrina. De hecho durante la Visita de 1560 la mayoría de los pueblos ni siquiera tenían capilla o cura doctrinero. En sitios como Labateca, el

\footnotetext{
${ }^{43}$ A.G.N. (Santafé de Bogotá), Real Audiencia de Santander, t. 13, f. 828r. ${ }^{44}$ Germán Colmenares, Encomienda y población, pp. 103-113.
} 
encomendero llevaba los indios a sus "aposentos" para enseñarles las oraciones y escasamente los "hacían cristianos" al momento de morir. ${ }^{45}$

Existía una amplia gama de cultivos. El principal, por supuesto, era el maíz, pero junto a él se cultivaban la yuca, los frijoles, las turmas, las batatas, ají, algodón, fique, etc., dependiendo de las condiciones geográficas y climáticas del lugar. También se introdujeron cultivos europeos como el trigo y la caña de azúcar, que los encomenderos vendían luego en los mercados locales.

Las labranzas se hacían en algunos lugares una o dos veces al año, dependiendo del producto. Por ejemplo en 1572 los indios de Panaga hacían una labranza de trigo de fanega y media y dos labranzas de maíz de ocho fanegas al año para el encomendero. Además tres gañanes y algunos vaqueros trabajaban cuidando el ganado. Con los bueyes de su amo araban los campos de trigo. Sobre este cultivo, el Cacique Fernando anotó:

"...La Tierra la aran los bueyes, el cristiano lo siembra y los dichos indios lo recogen. Los caballos lo desparraman y los indios lo limpian" 46

Por su trabajo en las labores del campo, ya fuera sembrando o como vaqueros, gañanes o arrieros, los indios recibían algunas cosas de sus amos. Los de Panaga recibían mantas, camisetas y sal. ${ }^{47} \mathrm{~A}$ los de Ima, encomendados en Gómez Hernández, se les daba en 1591 mantas, sal y algo de carne en ocasiones especiales. ${ }^{48}$ Los de Bochalema, por su parte, declararon en 1602 que servían de gañanes, vaqueros y araban la tierra durante 3 meses al año. También le hacían al encomendero algunas labranzas de caña y maíz de 3 o 4 fanegas. Los labradores recibían cada año una manta y una camiseta de lana por su trabajo, mientras que los gañanes, arrieros y vaqueros recibían mantas, camisetas, cuchillos, sal, agujas y machetes. ${ }^{49}$ Estos indios eran importantes dentro de la economía local de los españoles, ya que los vaque-

\footnotetext{
${ }^{45}$ Visita de Tomás López (1560), Visitas de Santander, t. 9, ff. 944r-949v.

${ }^{46}$ Visita de Juan Suárez de Cepeda (1572), A.G.N. (Santafe de Bogotá), Caciques e Indios, t. 32, f.363v.

${ }^{47}$ Ibid.

${ }^{48}$ Visita de Francisco de Berrío (1591), Caciques e indios, t. 32, f. 406r.

49 Visita de Beltrán de Guevara (1602), Visitas de Santander, t. 5, f. 672r.
} 
ros se encargaban de cuidar los hatos ganaderos que habían comenzado a extenderse por los valles de la provincia y los arrieros hacían circular los productos llevándolos a la ciudad, a los mercados y a las minas. ${ }^{50}$

Otras actividades importantes fueron los textiles y la bija. La producción de mantas estaba localizada en dos grandes zonas de la provincia: los valles de Labateca (Valle de los Locos) e Ima, al suroriente, y los valles de Guaca y Servitá, al suroccidente, en la vertiente del río Chicamocha. La primera zona era habitada por tribus Chitareras, mientras que la segunda se ubicaba en la frontera con los Guanes y muy posiblemente estaba poblada por comunidades de esta filiación. La producción de bija estaba más dispersa por toda la Provincia y no se han logrado identificar zonas especializadas. Aunque en muchos pueblos se mencionó en 1559 la presencia de bija como producto autóctono o como producto de intercambio, solamente las encomiendas de Nyalita, Chinácota, Ima y Tangacha la daban como tributo. ${ }^{51}$

Las mantas no sólo eran elaboradas con fibras de algodón. Algunas comunidades como los indios de Arola de Alonso de Parada, visitados en 1572 por Juan Suárez de Cepeda, dijeron que eran muy pobres y no tenían algodón. Por eso tejían su ropa con cabuya y no le daban mantas al encomendero. $^{52}$ La mayoría de las comunidades productoras de textiles lo hacía con el algodón que cultivaban o adquirían al intercambiarlo por maíz, bija y otros productos. Se utilizaban métodos tradicionales, ya que no se ha encontrado ningún indicio que pruebe o sugiera la existencia de obrajes organizados por los encomenderos durante el siglo XVI, como sucedía en otras provincias. Sólo hasta las primeras décadas del siguiente siglo, es decir hacia 1620, encontramos indias trabajando en obrajes hilando algodón y tejiendo mantas a las órdenes de la encomendera, en los aposentos de Guaca y Bucarica. ${ }^{53}$

Un dato curioso es que las mantas de la Provincia de Pamplona no eran consideradas de muy buena calidad por los mismos indios. Por ejemplo en 1591, Diego Juanapa, de la encomienda de Ima Subcana, dijo al Visitador

\footnotetext{
50 Silvano Pabón, Historia del Poblamiento, p. 123.

51 Visita de Cristóbal Bueno (1559), ff. 727r-v, 847r, 820r-v y 823v-824r.

52 Visita de Juan Suárez de Cepeda (1572), Caciques e Indios, t. 32, f. 362v.

53 Visita del Oidor Juan de Villabona y Zubiaurre (1622), Visitas de Boyacá, t. 11, ff. 590r-600v.
} 
Francisco de Berrío que sus mantas no eran muy buenas y que el encomendero solía vender aquellas que le entregaban como tributo, para comprar otras en el Nuevo Reino (Provincias de Tunja y Santa Fé), que luego repartía a los indios trabajadores. ${ }^{54}$

\section{c) Otras labores}

Además de servir en labores agrícolas, ganaderas y textiles, los indios eran empleados como pajes, sirvientes o artesanos. Los conquistadores y encomenderos solían tener algunos muchachos como sirvientes personales que los acompañaban a todas partes y cuidaban de los caballos y efectos personales durante los viajes. También algunas niñas eran sacadas de sus comunidades para servir en las labores domésticas de los aposentos de la encomienda o en la casa de sus amos en Pamplona, bajo las órdenes de las encomenderas. Estas niñas y niños de corta edad aprendían con mayor facilidad el idioma y las costumbres de los blancos, con lo cual se convertían en útiles intermediarios frente a sus comunidades. Los indios "ladinos", como eran llamados, se ganaban la confianza de sus amos y eran usados con frecuencia como intérpretes de las Visitas.

Los indios de Gómez Hernández contaron al Juez Francisco de Berrío en 1591 que su amo había sacado seis niñas del pueblo de Ima y otras dos del pueblo de Pisacuta para que le sirvieran a su mujer en la casa. ${ }^{55}$ Allá lavaban la ropa, cocinaban, limpiaban y se ocupaban del aseo. También hacían de damas de compañía, peinaban y ayudaban a vestir a la encomendera. Por su trabajo no se les daba sino la comida y sus parientes, que se quedaban en sus pueblos de origen, les llevaban ropa y otras cosas cada vez que iban a visitarlas.

Sobre las labores que desarrollaban estos sirvientes, tanto los muchachos como las jóvenes, tenemos poca información, ya que las Visitas se centraban especialmente en los indios del campo y de las minas, descuidando un poco aquellos que eran llevados a la ciudad de Pamplona o a los aposentos del encomendero. Sin embargo tenemos para el siglo XVII un documento interesante que muestra algunas actividades realizadas por las mujeres bajo las

\footnotetext{
${ }^{54}$ Visita de Francisco de Berrío (1591), Caciques e Indios, t. 32, f. 406r.

55 Visita de Francisco de Berrío (1591), Caciques e Indios, t. 32, f. 398r-406v.
} 
órdenes de las encomenderas. Se trata de la Visita realizada en 1622 por el Oidor Juan de Villabona a los repartimientos de Guaca y Bucarica, cerca del Río del Oro. En esa ocasión, cerca de 42 mujeres acudieron con sus esposos a quejarse ante el Visitador por los malos tratos a que los sometía la mujer de Juan de Velasco. La mayoría trabajaba en el obraje hilando algodón, pero también había varias jóvenes que se ocupaban de lavar la ropa, hacer el aseo, vestir a su ama, fabricar ollas de barro y hacer quesos, tasajos y conservas, que luego debían llevar a las minas para vender a los trabajadores. Incluso algunas niñas de 7 a 8 años eran empleadas en tareas tales como "quitarle los mosquitos" a la encomendera o darle viento en los días calurosos. ${ }^{56}$

Otro grupo de indios, cuyo trabajo es importante reseñar, está constituido por los forasteros provenientes de las provincias de Tunja, Vélez y Santa Fé que habían huido de sus repartimientos y se hallaban en la ciudad de Pamplona a finales del siglo XVI. Estos indios se contrataban mediante "conciertos de servicio" para las labores agrícolas y mineras, pero también para una serie de oficios artesanales en la ciudad. Pabón ha calculado que más del $80 \%$ de los indios forasteros que acudieron a registrar conciertos ante el escribano público de Pamplona era de origen Muisca. En segundo lugar se presentaron indios de Venezuela, provenientes de Mérida, La Grita y San Cristóbal. Por último había indios de Muzo, los Llanos, Vélez, Chita, Cocuy, Ocaña y hasta del Virreinato del Perú. Al llegar a Pamplona eran contratados como capataces o "calpixques" en las minas y en las haciendas, como sirvientes, y también como artesanos en la ciudad, desarrollando oficios de alfareros, ladrilleros, molineros, zapateros, curtidores, sastres, etc. Sus salarios eran pagados de forma variada. Se podían ganar desde 2 mantas, hasta 60 pesos al año, dependiendo de la actividad que desarrollaran. Pabón anota que un arriero ganaba un promedio de 16 a 25 pesos de oro al año, un vaquero o gañán recibía entre 10 y 15 pesos de oro, una india del servicio doméstico podía ganar dos o tres mantas y un "chumbe", y un sastre o zapatero recibía unos 60 pesos al año, de acuerdo a su conocimiento del oficio. Su importancia en la ciudad era tal que en 1582 el vicario les hizo fundar una cofradía especial para ellos dedicada al culto de Santa Lucía. ${ }^{57}$

56 Visita del Oidor Juan de Villabona y Zub.iaurre (1622), Visitas de Boyacá, t. 11, ff. 590r-600v.

57 Silvano Pabón, Historia de la Construcción, pp. 127 y siguientes. 
Debido a las ventajas que representaba para los indios forasteros el vivir en la ciudad de Pamplona, donde ganaban relativamente buenos salarios y no estaban sometidos a la servidumbre de las encomiendas, no es de extrañar la creciente inmigración que se presentó a finales del siglo XVI y comienzos del XVII. La cantidad de indios oriundos de la misma Provincia de Pamplona que se encontraban concertados en la ciudad era mínima, seguramente porque era mucho más difícil pasar desapercibidos en un lugar donde todo el mundo los conocía y podía identificar el repartimiento del que provenían. Aquellos que huían de los repartimientos lo hacían seguramente hacia otras ciudades del Nuevo Reino o de la Gobernación de Venezuela. Sin embargo, el dejar atrás sus tierras y sus parientes era un precio demasiado alto para obtener mayor libertad y en realidad fueron pocos los que optaron por la huida de las encomiendas, si tenemos en cuenta el bajo número de ausentes que se reportaban en las Visitas. Además, los que huían lo hacían casi siempre de las minas, pero sólo para regresar a sus poblados de origen, donde eran fácilmente atrapados y reincorporados a las labores. $^{58}$

\section{Epílogo: la tasación de los tributos}

Los indios de la Provincia de Pamplona continuaron bajo el régimen de los "servicios personales" durante todo el siglo XVI y las primeras décadas del siglo XVII. En el año de 1602 una Visita realizada por el Corregidor Beltrán de Guevara con el fin de tasar los tributos concluyó sin ningún resultado, ya que el Visitador acogió la petición de indios y encomenderos para que dejara las cosas tal como las había encontrado. Los indios argumentaron que eran demasiado pobres para dar un tributo al encomendero y preferían seguir trabajando en las labranzas, dando muchachos para las minas y tejiendo mantas. Aunque es difícil saber si estas opiniones eran sinceras o eran fruto de la coacción de los encomenderos, la supuesta "pobreza" de los indios fue el factor determinante para que la decisión se aplazara de nuevo y todo continuara como había sido desde la conquista. ${ }^{59}$

58 Por ejemplo de los 1.046 indios que había en los tres Reales de minas en 1602, solamente se reportaron 5 ausentes del pueblo del Río del Oro, los cuales habían regresado a Guaca y Bucarica, de donde provenían. Ver tabla $\mathrm{N}^{\circ} 6$.

59 Ver las disposiciones tomadas durante la Visita del Corregidor Beltrán de Guevara (1602), Visitas de Santander, t. 5, ff. $1-118$. 
Sin embargo, en tan solo unos años las cosas cambiaron drásticamente. En el año de 1622 un nuevo Visitador recorrió la zona. El Oidor Juan de Villabona y Zubiaurre llevaba órdenes estrictas del Presidente de la Real Audiencia para intentar la reactivación de las ya decadentes minas de oro, juntar a los indios en pueblos al estilo español, reorganizar las doctrinas y tasar finalmente los tributos, diligencia que se venía tratando de realizar por más de 60 años. ${ }^{60}$ El clamor de los naturales para que se hiciera la tasación y cesara el servicio personal había venido aumentando en los últimos años. Comunidades como las de Guaca y Bucarica, de Juan de Velasco, el hijo del fundador de la ciudad, se quejaban del excesivo trabajo que tenían en las quebradas cercanas al Río del Oro, donde en medio del clima malsano eran obligados a entregar un jornal de uno a dos pesos a la semana. Las mujeres también se quejaron de las largas ausencias de sus maridos que duraban meses buscando oro en las quebradas, con lo cual ellas debían ocuparse de las labranzas y otra serie de tareas muy pesadas. Algunas incluso eran empleadas por la esposa del encomendero en los obrajes para hilar y tejer mantas, castigándolas cuando no cumplían las cuotas establecidas. Otras hacían carnes, quesos y conservas que luego debían cargar hasta las minas para venderle a sus maridos. Las demás fabricaban ollas de barro o eran empleadas como cocineras, sirvientas y lavanderas. ${ }^{61}$

Ante estas quejas el Visitador decidió reglamentar las jornadas de trabajo en las minas y en el campo, así como los salarios que se pagarían a los indios de acuerdo a las labores que realizaran, siguiendo las instrucciones que había recibido desde España. Luego organizó 10 pueblos con el casi centenar de encomiendas que todavía quedaban y tasó finalmente los tributos, tras 73 años de haberse repartido las primeras encomiendas. De ahora en adelante los indios mineros recibirían un salario diario de un tomín de oro (la octava parte de un peso) de 20 quilates y pagarían a su encomendero 7 pesos de 20 quilates al año como tributo, la mitad en la fiesta de San Juan

\footnotetext{
${ }^{60}$ Visita del Oidor Juan de Villabona y Zubiaurre (1622), Visitas de Boyacá, t. 11, ff. 590r-600v.

61 Las disposiciones tomadas por el Oidor Juan de Villabona en 1622 se encuentran en A.G.N. (Santafé de Bogotá), Impuestos Varios, t. 16, f. 405r. Las "Ordenanzas de Minas" redactadas por este visitador el 12 de febrero de 1623, que se encuentran en la Biblioteca del Real Palacio de Madrid bajo la signatura 2859, folios 186-239, han sido transcritas por Rafael Eduardo Ángel y publicadas por Armando Martínez Garnica y Amado Guerrero, La Provincia de Soto. Orígenes de sus poblatnientos urbanos, Bucaramanga, Universidad Industrial de Santander, 1995, pp. 187-217.
} 
y la otra mitad en Navidad. Los que permanecieran en el campo deberían pagar de ahora en adelante 4 pesos al año, también en dos contados. Cuando fueran llevados a trabajar su salario sería fijado mediante un contrato (o "concierto") de acuerdo a la labor que realizaran. ${ }^{62}$

Aunque estas medidas generaron una fuerte resistencia por parte de los encomenderos, al final éstos terminaron aceptando la nueva situación. Ya por aquel entonces la encomienda como institución económica y fuente de riqueza había entrado en decadencia. Las minas se habían agotado y las haciendas, que habían crecido por todas partes, eran explotadas cada vez más por personajes que no tenían encomiendas y preferían contratar indios o mestizos jornaleros. ${ }^{63}$

Los indios debían conseguir el dinero para pagar sus tributos, vendiendo sus productos o concertándose en las haciendas a cambio de un pequeño salario. Para los mineros, la consecución del oro era más fácil, pero los encomenderos impusieron la modalidad de pagar los salarios de los trabajadores descontándolos de los tributos. Con el tiempo esta costumbre también se fue adoptando en las haciendas donde los indios acudían a realizar labores agrícolas y ganaderas. ${ }^{64}$ De esta manera con unas 8 semanas de trabajo sin salario, el tributo quedaba cancelado. En 1622 ya eran muy pocos los encomenderos que explotaban minas y aproximadamente a partir de 1630 casi todos abandonaron la labor. Los indios continuaron viviendo en los poblados mineros, trabajando para ellos mismos o como empleados de algunos empresarios y pagaban el tributo al Alcalde Mayor, quien no lo hacía llegar al encomendero, sino que usaba el dinero para pagarse su salario y para pagar al cura del lugar. Por esos años, algunos indios de las minas ni siquiera conocían a su encomendero. ${ }^{65}$

El tributo destinado a los Caciques continuó en la medida en que estas autoridades tradicionales continuaron operando. A mediados del siglo XVII,

Visita de Juan de Villabona (1622), Impuestos Varios, t. 16, f. 405r.

63 Ver: Germán Colmenares, Encomienda y población, pp. 103-113.

64 En 1657 los indios de varias encomiendas declararon que les pagaban sus salarios como gañanes, arrieros y otros, en descuento de los tributos. Ver la Visita del Oidor Diego de Baños y Sotomayor (1657), A.G.N. (Santafé de Bogotá), Visitas de Santander, t. 3, f. 250r y siguientes.

65 Jorge Gamboa, "El Trabajo de los Indios en las Minas de Pamplona", Poblamiento regional, pp. 165-200. 
cien años después de la conquista, los indios del pueblo de Labateca seguían haciendo las labranzas de los Caciques en señal de reconocimiento de su autoridad. Lo novedoso era que ahora trabajaban "concertados" en las haciendas cercanas, pagando con sus salarios el tributo para el encomendero. ${ }^{66}$ Una investigación detallada sobre lo sucedido durante el siglo XVII, después de la tasación de tributos, podría arrojar luces sobre el impacto que esto tuvo en la vida de los indígenas y los procesos sociales que se dieron en la Provincia en una época en que la institución de la encomienda se encontraba en franca decadencia y en vías de desaparición. También podrá mostrar la forma como los Caciques y las autoridades tradicionales fueron desplazadas y reemplazadas por Gobernadores, Tenientes y Capitanes, surgidos en el marco de la sociedad colonial.

${ }^{66}$ Visita de Diego de Baños (1657), Visitas de Santander, t. 3, f. 42r. 


\section{BIBLIOGRAFIA}

\section{FUENTES PRIMARIAS}

\section{A. Fuentes Documentales}

Archivo General de la Nación (Santafé de Bogotá), sección Colonia.

Caciques e Indios, 32, 46, 65.

Impuestos Varios, 16. Miscelánea,

15, 85, 94. Poblaciones, 11. Visitas

de Boyacá, 6. Visitas de Santander,

3, 5,11.

\section{B. Crónicas y Documentos Impresos}

Aguado, Fray Pedro, Recopilación Historial. 4 vols., Bogotá, Biblioteca de la Presidencia de la República, 1956.

Colmenares, Germán, (Transcripción), Fuentes Coloniales para la Historia del Trabajo en Colombia, Bogotá, Editorial Universidad de los Andes, 1968.

Friede, Juan, (Transcripción), Fuentes Documentales para la Historia del Nuevo Reino de Granada desde la instalación de la Real Audiencia de Santafé, t. 1, Bogotá, Biblioteca Banco Popular, 1975.

López, Tomás, Colonización de América. Informes y Testimonios, (Compilado por Luciano Pereña, C. Baciero y F. Maseda), Madrid, Consejo Superior de Investigaciones Científicas, 1990.

Primer Libro de Actas del Cabildo de la Ciudad de Pamplona en la Nueva Granada 1552-1561, Dirección, prólogo e índice razonado por Enrique Otero D'Costa, Bogotá, Academia de Historia Colombiana, 1950. 
Tovar Pinzón, Hermes, (Transcripción), "Visita de 1560 (Anónima)", No Hay Caciques ni Señores, Barcelona, Editorial Sendai, 1988.

\section{Bibliografía Moderna}

Backewell, Peter, Mineros de la Montaña Roja, Madrid, Alianza Editorial, 1989.

Colmenares, Germán, Encomienda y Población en la Provincia de Pamplona (1559-1650), Bogotá, Universidad de los Andes, 1969.

Gamboa, Jorge, "El Trabajo de los Indios en las Minas de Pamplona", Poblamiento Regional, Etnohistoria y Etnografía en Pamplona. Memorias del I Simposio de Historia Regional "Pamplona 445 años ", Cúcuta, Cámara de Comercio, 1995, pp. 165-200.

Gibson, Charles, "Las Sociedades Indias bajo el dominio español", Historia de América Latina, t. 4, Barcelona, Editorial Crítica, 1990, pp. 157-188.

Langebaek, Karl, Mercados, Poblamiento e Integración Etnica entre los Muiscas. Siglo XVI, Bogotá, Banco de la República, 1987.

Mair, Lucy, Gobierno Primitivo, Buenos Aires, Amorrortu Editores, 1970.

Murra, John, La Organización Económica del Estado Inca, México, Siglo XXI, 1978.

Pabón, Silvano, Historia del Poblamiento y Construcción del Espacio Hispánico en Pamplona, Cúcuta, Cámara de Comercio, 1996.

Pabón, Silvano, Los Chitareros: Pobladores Prehispánicos de Sierras Nevadas, Antigua Provincia de Pamplona, Cúcuta, 1992. Mecanografiado.

Rodríguez, Luis Emique, Encomienda y Vida diaria entre los Indios de Muzo (1550-1620), Bogotá, Instituto Colombiano de Cultura Hispánica, 1995. 
Stern, Steve, Los Pueblos Indígenas del Perú y el desafío de la Conquista Española, Madrid, Alianza Editorial, 1990.

Tovar Pinzón, Hermes, "Estado Actual de los Estudios de Demografía Histórica en Colombia", Anuario Colombiano de Historia Social y de la Cultura, N 5, Bogotá, Universidad Nacional de Colombia, 1970, pp. 65-140. 